\title{
DESTILAÇÃO ATMOSFÉRICA DO BIODIESEL DERIVADO DO ÓLEO DE MACAÚBA OU DO PALMISTE PARA OBTENÇÃO DA FRAÇÃO DE ÉSTERES LEVES PARA USO COMO COMBUSTÍVEL DE AVIAÇÃO
}

\author{
Luiz Vitor Leonardi Harter,*, Douglas Queiroz Santosª e José Domingos Fabris ${ }^{\mathrm{b}, \mathrm{c}}$ \\ ${ }^{a}$ Escola Técnica de Saúde, Universidade Federal de Uberlândia, 38408-100 Uberlândia - MG, Brasil \\ bDepartamento de Química, Instituto de Ciências Exatas, Universidade Federal de Minas Gerais, Campus Pampulha, 31270- \\ 901 Belo Horizonte - MG, Brasil \\ 'Instituto de Química, Universidade Federal de Uberlândia, 38400-902 Uberlândia - MG, Brasil
}

Recebido em 04/07/2018; aceito em 24/10/2018; publicado na web em 20/12/2018

\begin{abstract}
ATMOSPHERIC DISTILLATION OF BIODIESEL FROM MACAÚBA OR PALMISTE OIL TO OBTAIN LIGHTER ESTER FRACTION TO BE USED AS AVIATION FUEL. The production of methyl esters via transesterification reaction of triacylglycerides of macaúba and palm kernel oils, with subsequent atmospheric distillation and separation of six fractions of the produced biodiesel, corresponding to $60 \%$ of its initial volume, is reported. The composition in esters of the produced biodiesel, its fractions and remaining residue of the distillation was determined by gas chromatography. This analytical procedure has allowed to monitor the content in esters for each distilled fraction. The fractions richer in C8:0, C10:0, C12:0, C14:0 is intended to be used as an aviation fuel, in blends with the Jet-A1 biokerosene. The residues from the distillation with higher molecular weights than those corresponding to esters $\mathrm{C} 16: 0, \mathrm{C} 18: 0$ and $\mathrm{C} 18: 1$ are destined to other combustion engines as any conventional biodiesel. For the biodiesel obtained from the macaúba kernel, this distillation led to an enrichment from $45.86 \%$ to up to $74.35 \%$ in the C12:0 ester. For the palm kernel biodiesel, the corresponding enrichment was from $66.76 \%$ up to $82.96 \%$. Through this simple distillation, it was thus possible to effectively enrich, in C8:0 to C14:0 esters, the initial crude biofuel, with an efficiency of 30\% for the macaúba and 11.5\% for the palmiste biodiesel.
\end{abstract}

Keywords: biokerosene; distillation; palm; macaúba.

\section{INTRODUÇÃO}

A aplicação de biocombustíveis (especialmente do biodiesel) no segmento de aviação tem sido uma tendência global, particularmente nestes tempos de mudanças climáticas, em que os governos nacionais precisam se ajustar à políticas energéticas e a uma economia de baixo carbono, para honrar suas metas obrigatórias ou voluntárias de emissões de gases do efeito estufa (GEE). ${ }^{1}$

Para fins de produção de biodiesel, o óleo extraído das amêndoas do babaçu, por ter composição predominante de triacilgliceróis de ácido láurico (C12:0; cadeia molecular relativamente curta), foi considerado ser de qualidades favoráveis para uso em motores de avião. ${ }^{2} \mathrm{O}$ óleo do babaçu tem composição em ácidos graxos comparável ao do óleo da amêndoa de macaúba e ao óleo de palmiste. Os óleos dos frutos dessas palmáceas (família Arecaceae) têm relativamente teores maiores de ácido caprílico (C8:0), ácido cáprico (C10:0), ácido láurico (C12:0) e ácido mirístico (C14:0), resultando assim em ésteres de cadeias moleculares relativamente curtas; são os denominados ésteres leves, podendo ser utilizados na produção de blends com o querosene mineral de aviação (QAV), que é um derivado de petróleo obtido da destilação direta, sob temperatura entre $150^{\circ} \mathrm{C}$ e $300^{\circ} \mathrm{C}$. O querosene mineral é constituído por hidrocarbonetos parafínicos, alifáticos, naftênicos e aromáticos, com estrutura molecular com número de átomos de carbono variando de 9 a 15; é líquido na temperatura do ambiente.

Os ésteres produzidos com os óleos de amêndoa de macaúba de palmiste apresentam composição em relação a tamanho de cadeia molecular comparável ao QAV, podendo ser utilizados para blends com o querosene fóssil, como é feito para o diesel, desde que atenda os parâmetros físicos de qualidade.

*e-mail: vitorharter@ufu.br
Considerando o disposto na Lei ${ }^{\circ} 12.490$, de 16 de setembro de 2011, que define bioquerosene de aviação como substância derivada de biomassa renovável que pode ser usada em turborreatores e turbo propulsores aeronáuticos ou, conforme regulamento, em outro tipo de aplicação que possa substituir parcial ou totalmente o combustível de origem fóssil. ${ }^{3}$ Porém, ao contrário do uso de combustíveis alternativos em outros setores, a aviação requer restrição de rigor muito maior, para qualquer que seja o combustível candidato, devido a vários fatores. Em primeiro lugar, as condições extremas em que a combustão é submetida devem ser confiáveis e seguras, o que impõe um limitado leque de combustíveis líquidos potenciais. Finalmente, a longa vida útil das aeronaves comerciais implica que qualquer combustível candidato precisa ser compatível e adequado para utilização em motores com as tecnologias já existentes. ${ }^{4}$

As companhias aéreas, fabricantes, empresas químicas e os governos estão agindo para buscar atender as necessidades de abastecimento de aeronaves. O querosene de aviação atingiu, a partir de 2006, o patamar de componente de maior custo operacional para as companhias aéreas. Além dos elevados preços do petróleo, os limites máximos às emissões de carbono, estabelecidos em janeiro de 2012, levaram o setor a investir centenas de milhões de dólares para o desenvolvimento de uma fonte de energia mais segura, acessível e menos danosa ao ambiente..$^{5,6} \mathrm{~A}$ taxa relativa de crescimento do setor, aliada às preocupações ambientais e em torno do futuro do abastecimento, acelerou a busca por combustíveis alternativos, em significativa proporção, renováveis. Por essas razões, um importante foco das pesquisas tem sido em torno do desenvolvimento de combustíveis drop in, termo utilizado para combustíveis alternativos que podem ser usados na frota existente, sem necessidade de alterações nos motores das aeronaves. ${ }^{4} \mathrm{O}$ bioquerosene, legalmente entendido como querosene sintético parafínico (Bio-SKP, sigla da denominação em inglês Bio-derived Synthetic Paraffinic Kerosene), derivado 
da biomassa, ou, na visão prática, misturas de querosene fóssil com proporções limitadas de ésteres de ácidos graxos leves (de C8 a C14), é uma alternativa interessante para o mercado, por ser ambientalmente menos prejudicial e apresentar composição química semelhante ao querosene fóssil.

A Sociedade Americana de Testes de Materiais (ASTM) publicou, recentemente, os métodos aprovados para a produção alternativa de combustíveis de aviação. São eles, basicamente, o método de biomassa para líquido (BtL), que inclui o processo de Fischer-Tropsch (FT); e o de ésteres e ácidos graxos hidroprocessados (HEFA; sigla da denominação em inglês, Hydro-processed Esters and Fatty Acids), os quais podem ser usados numa proporção volumétrica de até $50 \%$ com o QAV. ${ }^{7}$

Segundo o regulamento técnico da Resolução da ANP n ${ }^{\circ}$ 63, de 5 de dezembro de $2014,{ }^{8}$ baseada na Lei $\mathrm{n}^{\circ} 12.490$, de 16 de setembro de $2011,{ }^{3}$ existem duas definições para a síntese e composição dos querosenes alternativos de aviação: querosene parafínico sintetizado hidroprocessado (SPK-HEFA) e sintetizado pela via Fisher-Tropsch (SPK-FT): componente sintético da mistura que compreende essencialmente isoparafinas, n-parafinas e cicloparafinas, obtidas de um ou mais precursores produzidos pelo processo Fischer-Tropsch (FT; usando-se catalisadores de ferro ou cobalto). ${ }^{8}$ Para o SPK-HEFA, o querosene parafínico é obtido pela hidrogenação e desoxigenação de ésteres de ácidos graxos e ácidos livres com objetivo de remover essencialmente o oxigênio.

A matriz de energia do Brasil agrega produção sustentável, segurança alimentar e desenvolvimento rural. Mesmo com a tecnologia já existente para a produção do biodiesel, o Brasil esbarra na falta de investimentos suficientes e de políticas públicas que sejam mais vigorosamente estimuladoras à pesquisa científica, ao desenvolvimento tecnológico e à produção industrial de bioquerosene para aviação civil, na escala nacional. ${ }^{9}$

D. A. Wardle sustenta ampla argumentação técnica para o uso de baixas concentrações de biodiesel em mistura com o querosene mineral, para uso na propulsão de aeronaves comerciais. ${ }^{10}$ Tal proposta implica o uso de biodieseis com composição em ésteres metílicos que permitissem a preservação de características críticas da mistura combustível, para aviões. Uma dessas características é o ponto de congelamento do líquido, que, para turbinas de jatos, deverá ser, de no máximo, $-40^{\circ} \mathrm{C}$ (especificação para os querosenes de aviação alternativos SPK - FT ou SPK - HEFA), ${ }^{11}$ ou $-47{ }^{\circ} \mathrm{C}$, para o QAV, fóssil. ${ }^{12} \mathrm{O}$ enriquecimento em ésteres relativamente mais leves, de cadeia molecular mais curta é apenas um dos desafios. Damasceno et al. reportam a separação da fração enriquecida em ésteres de menor cadeia molecular de biodiesel preparado de óleo de amêndoa do fruto da macaúba, com uma coluna com leito fixo de material adsorvente, com uma peneira molecular comercial ou com carvão ativado. ${ }^{13}$

Llamas et al. utilizaram a fração mais leve, obtida por destilação a vácuo de ésteres metílicos de óleos de coco e de palmiste. Os ésteres metílicos leves, de baixo ponto de ebulição, foram misturados nas razões volumétricas convencionais de 5\%,10\% e 20\%, com dois tipos de querosene fóssil (QAV). As misturas atenderam a algumas especificações selecionadas para o estudo. ${ }^{14}$

O combustível alternativo para aviação obtido de matérias-primas sustentáveis deve atender a determinados requisitos de segurança e apresentar propriedades físico-químicas semelhantes ao querosene mineral. Oliveira et al. avaliou a produção de biocombustível enriquecido com ésteres de cadeia curta, utilizando a destilação molecular de FAME (Fatty Acid Methyl Ester) obtido do óleo de babaçu. Um combustível com propriedades próximas às dos biocombustíveis de aviação foi obtido a $140{ }^{\circ} \mathrm{C}$. A essa temperatura, mais de $80 \%$ dos ésteres na composição do produto estavam dentro do intervalo desejado e houve uma recuperação de massa superior a $88 \%$. Além disso, o biocombustível enriquecido com ésteres de cadeia curta foi misturado com querosene fóssil em diferentes concentrações e suas propriedades foram analisadas, para avaliar os efeitos da adição gradual desse biocombustível ao querosene de aviação comercial. ${ }^{15}$

No trabalho de pesquisa aqui reportado, buscou-se utilizar bio-óleos com maiores teores em ácido láurico (C12:0), mas também de C8:0, C10:0 e C14:0. Para isso, escolheu-se o óleo das amêndoas dos frutos da macaúba (Acrocomia aculeata) e do dendê (Elaeis guineensis), ou palma (tal óleo, denominado palmiste), na produção de bioquerosene alternativo, via transesterificação metílica e catálise alcalina homogênea, com posterior destilação atmosférica dos ésteres mais leves, para obtenção de destilado enriquecido em C8:0 a C14:0, tamanhos de cadeias carbônicas dominantes dos hidrocarbonetos do QAV.

\section{PARTE EXPERIMENTAL}

\section{Produção do biodiesel de óleo de amêndoa da macaúba e de palmiste}

O biodiesel foi obtido via transesterificação metílica do óleo de amêndoa da macaúba e do palmiste, utilizando-se como catalisador o hidróxido de potássio. Na sequência, realizou-se a separação e a purificação do biodiesel produzido, de acordo com o seguinte procedimento experimental: foram pesados $400 \mathrm{~g}$ de óleo vegetal, $80 \mathrm{~g}$ de metanol e $4 \mathrm{~g}$ de hidróxido de potássio. Após a mistura completa do metanol com o hidróxido de potássio, foi misturado o óleo vegetal, permanecendo em agitação por um período de $50 \mathrm{~min}$. O biodiesel e a glicerina formados foram separados em funil de decantação; a mistura binária foi posta em repouso por $24 \mathrm{~h}$, para posterior separação da glicerina. $\mathrm{O}$ biodiesel resultante passou por lavagem com $\mathrm{HCl}$ $0,1 \mathrm{~mol} \mathrm{~L}{ }^{-1}$ e com água a $80^{\circ} \mathrm{C}$. Ainda com o objetivo de purificação, o biodiesel produzido foi levado em rotaevaporador a $95^{\circ} \mathrm{C}$ por $1 \mathrm{~h}$. Em seguida, foi posto em estufa a $105^{\circ} \mathrm{C}$ por $2 \mathrm{~h}$. Os biodieseis produzidos foram devidamente armazenados para realização da destilação simples com corte em frações e também com recolhimento de $60 \%$ do volume disponibilizado para destilar.

\section{Destilação simples com cortes - concentração dos ésteres leves}

O biodiesel produzido passou por processo de destilação simples com cortes, realizada a pressão atmosférica, utilizando para isso um aparelho de destilação, composto de balão de fundo redondo de $1000 \mathrm{~mL}$, coluna de destilação do tipo vigreux de $300 \mathrm{~mm}$, junta de conexão com saída lateral para conexão de condensador e abertura superior para conexão de rolha perfurada com inserção de termômetro. A coluna de destilação foi isolada com utilização de lã de vidro e revestimento com papel alumínio. Como fonte de aquecimento foi utilizada uma manta.

\section{Destilação simples com cortes em frações}

Para estudo da composição do destilado em relação ao teor de ésteres, foi realizada a destilação de $250 \mathrm{~mL}$ de cada biodiesel produzido, sendo recolhidas seis frações consecutivas de $25 \mathrm{~mL}$, armazenadas separadamente. As temperaturas do topo da coluna foram monitoradas e registradas durante o processo. O total de volume recolhido corresponde a $60 \%$ do total de biodiesel disponibilizado para a destilação. Permitindo assim acompanhar a concentração dos ésteres durante o corte em frações do destilado, verificando a variação nos teores, possibilitando adotar um melhor ponto de corte da destilação, para obtenção de destilados com maiores teores de C8 a C14 e menores teores em C18:0 e C18:1. 
O resíduo de fundo do balão foi retirado e armazenado, para posterior análise da composição em relação aos ésteres presentes, também para o biodiesel e as seis frações. A análise da composição do biodiesel produzido, do resíduo de fundo da destilação e das 6 frações destiladas, em relação ao tamanho das cadeias carbônicas dos ésteres formados, de C8:0, C10:0, C12:0, C14:0, C16:0, C18:0 e C18:1, foram realizadas através da metodologia adaptada EN 14103, em um cromatógrafo a gás HP7820A equipado com detector por ionização de chamas. Utilizouse uma coluna HP-INNOWAX (HP) $15 \mathrm{~m}$ x 0,25 mm x 0,25 $\mu \mathrm{m}$ com gradiente de temperatura: $70^{\circ} \mathrm{C}$, com aquecimento de $10^{\circ} \mathrm{C} / \mathrm{min}$ até 220 ${ }^{\circ} \mathrm{C}$; injetor (split de $1 / 50$ ) a $250^{\circ} \mathrm{C}$ e detector a $260^{\circ} \mathrm{C}$. Hélio como gás de arraste ( $3 \mathrm{~mL} / \mathrm{min})$. Volume de injeção de $1 \mu \mathrm{l}$. Tempo de corrida de cada injeção de aproximadamente 30 minutos. Nas amostras $(\sim 10 \mathrm{mg})$ foi adicionado $1 \mathrm{~mL}$ de solução de heptadecanoato de metila (C17:0) a $1,78 \mathrm{mg} / \mathrm{mL}$ como padrão interno.

\section{RESULTADOS E DISCUSSÃO}

\section{Temperaturas de retirada das frações destiladas}

As temperaturas de retirada das frações de cada biodiesel foram registradas com auxílio de termômetro instalado no topo da coluna de destilação e anotadas no início da retirada do volume de $25 \mathrm{~mL}$ e ao final de cada coleta. Os valores das temperaturas são apresentados na Tabela 1.

É possível verificar que a temperatura de início da destilação foi a mesma para os dois biodieseis utilizados, $110{ }^{\circ} \mathrm{C}$. Seguindo uma tendência de aumento proporcional ao tempo de destilação, a partir das segundas frações coletadas. Verifica-se também que, na destilação do biodiesel do palmiste, foram registradas temperaturas maiores, em relação ao biodiesel da macaúba, o que pode ter influenciado a eficiência da destilação, na concentração dos ésteres de menor cadeia molecular, fato que pode ter sido ocasionado pelo uso de manta de aquecimento, por não permitir um controle do aquecimento com maior precisão. O maior valor registrado para o biodiesel de macaúba foi de $230^{\circ} \mathrm{C}$, no final da retirada da fração 3 . Para o biodiesel de palmiste, o maior valor registrado foi de $269^{\circ} \mathrm{C}$, para a fração 5 .

\section{Composição do biodiesel, frações destiladas e resíduo}

Os respectivos cromatogramas gerados para os biodieseis de amêndoa de macaúba e palmiste são apresentados abaixo, Figura 1.

O primeiro pico do cromatograma é do solvente, heptano, utilizado para diluição da amostra. Os demais são dos ésteres presentes, com os respectivos tempos de retenção, em minutos. Para o C8:0, 4,17 min; C10:0, 7,13 min; C12:0, 10,35 min; C14:0, 13,48 min; C16:0, 16,70 min, C18:0, 20,06 min e C18:1, 23,73 min. O padrão interno utilizado $\mathrm{C} 17: 0$, heptadecanoato de metila, apresentou 19,38 min de tempo de retenção.

Através da análise cromatográfica dos produtos obtidos foram encontrados os resultados da porcentagem de ésteres metílicos, em relação ao tamanho da cadeia carbônica.
Conforme descrito anteriormente, foi realizada a destilação de $250 \mathrm{~mL}$ do biodiesel produzido, sendo recolhidas seis frações consecutivas de $25 \mathrm{~mL}$, armazenadas separadamente, correspondendo a $60 \%$ do total de biodiesel disponibilizado para a destilação.

\section{Para o biodiesel de amêndoa de macaúba}

São apresentados os resultados das análises cromatográficas para o biodiesel produzido, frações e resíduo, Tabela 2 e Figura 2.

Da Figura 2, tem-se que o biodiesel de amêndoa de macaúba apresentou $42 \%$ de ésteres metílicos com 12 carbonos, confirmando que o óleo de amêndoa de macaúba é rico em ácido láurico. O biodiesel apresentou aproximadamente $82 \%$ de ésteres com cadeia entre 8 a 14 carbonos.

Na destilação em frações, observou-se nas primeiras um maior teor em ésteres de cadeia curta, entre 8 a 12 carbonos. Para o C8:0 e C10:0 os maiores teores foram encontrados na fração 1, 38,49\% e 11,16\%, respectivamente, nas demais frações houve um declínio, sendo na fração 6, os valores $0,26 \%$ e $0,27 \%$. Das frações 1 a 6 , o teor de C12:0, foi de $46 \%$ até $31,6 \%$; o maior valor foi encontrado na fração $3,74,35 \%$. O C14 variou de $2,20 \%$ a $17,20 \%$. Para o C16, o teor variou de $0,77 \%$ a 13,24\%. O C18:0 e o C18:1, apresentaram teores de 1,52\% na fração 1 até $37,40 \%$ na fração 6 , indicando que o ponto para o melhor corte seria entre as frações 5 e 6 . O resíduo da destilação apresentou os maiores teores de C18:0/C18:1, com maiores temperaturas de destilação. Considerando os ésteres de cadeia curta, C8:0, C10:0, C12:0 e C14:0, presentes no biodiesel em relação aos mesmos ésteres presentes nos destilados, tem-se uma eficiência de $35 \%$.

Para acompanhamento do processo de destilação e da qualidade dos produtos, foram determinados o balanço de massa e a massa específica, apresentados na Tabela 3.

Verifica-se aumento proporcional dos valores da massa específica das frações, tendo como média $871,4 \mathrm{~kg} \mathrm{~m}^{-3}$, pois no início do processo têm-se, nas primeiras frações, maiores concentrações de ésteres com menor tamanho de cadeia, apresentando densidades menores. Durante o desenvolvimento do processo, as concentrações dos ésteres de maior cadeia vão aumentando e os de menor cadeia vão se esgotando, acarretando num aumento proporcional da massa específica. O resíduo da destilação apresentou maior massa específica, devido a maior presença de ésteres C18:0/ C18:1. A partir do balanço de massa do processo de destilação, tem-se que $0,2230 \mathrm{~kg}$ de biodiesel foram utilizados na destilação, e foram produzidos $0,1308 \mathrm{~kg}$ de destilado e $0,0922 \mathrm{~kg}$ de resíduo da destilação, no total. É possível utilizar os dados da Tabela 2 e calcular a massa de cada éster para cada fração.

\section{Para o biodiesel de palmiste}

São apresentados os resultados das análises cromatográficas para o biodiesel produzido, frações e resíduo, Tabela 4 e Figura 3.

Da Figura 3, tem-se que o biodiesel de palmiste apresentou maior teor em ésteres metílicos com 12 carbonos, de 55\%, confirmando também que o óleo de palmiste é rico em ácido láurico, apresentando maior proporção do que no biodiesel de macaúba. Porém, o biodiesel

Tabela 1. Temperaturas de acompanhamento da destilação na separação em frações

\begin{tabular}{|c|c|c|c|c|c|c|c|}
\hline \multirow{2}{*}{ Amostra } & \multirow{2}{*}{ Temperatura $\left({ }^{\circ} \mathrm{C}\right)$} & \multicolumn{6}{|c|}{ Fração } \\
\hline & & 1 & 2 & 3 & 4 & 5 & 6 \\
\hline \multirow{2}{*}{ Macaúba } & Início & 110 & 203 & 228 & 232 & 228 & 217 \\
\hline & Fim & 200 & 225 & 230 & 229 & 217 & 224 \\
\hline \multirow{2}{*}{ Palmiste } & Início & 110 & 230 & 257 & 265 & 269 & 242 \\
\hline & Fim & 225 & 255 & 263 & 268 & 245 & 213 \\
\hline
\end{tabular}


(A)Biodiesel óleo de amêndoa de macaúba



(B) Biodiesel óleo de palmiste

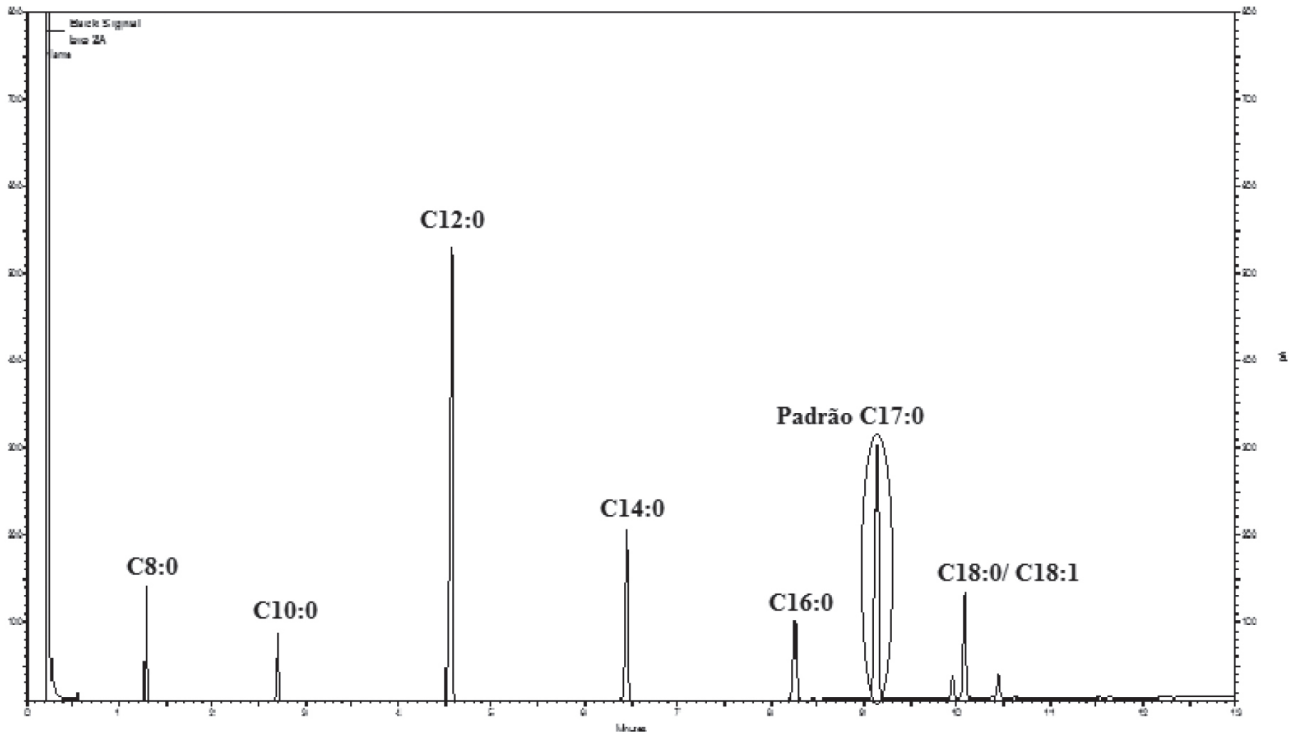

Figura 1. Representação de cromatograma da análise do teor de ésteres: (A) biodiesel de amêndoa de macaúba e (B)biodiesel de palmiste

apresentou aproximadamente $73 \%$ de ésteres com cadeias entre 8 a 14 carbonos, menor valor que o biodiesel de macaúba.

$\mathrm{Na}$ destilação em frações, observou-se nas primeiras um maior teor em ésteres de cadeia curta, entre 8 a 12 carbonos. Para o C8:0 e C10:0 os maiores teores foram encontrados na fração 1, 17,89\% e $9,03 \%$, respectivamente; nas demais frações houve um declínio, sendo na fração $6,0,07 \%$ e $0,26 \%$. Das frações 1 a 6 , o teor de $\mathrm{C} 12$, foi de $66,76 \%$ até $53,04 \%$; o maior valor encontrado foi na fração 2 , $82,96 \%$. O C14:0 variou de $4,12 \%$ a $25,92 \%$. Para o C16:0, o teor variou de $1,05 \%$ a 9,24\%. O C18:0 e C18:1, apresentaram teores de $1,16 \%$, na fração 1 , até $11,47 \%$ na fração 6 , indicando que o ponto para o melhor corte está entre as frações 5 e 6 , pois na sexta fração ocorre aumento do teor de C14:0, ainda dentro da faixa de ésteres de interesse na separação. O resíduo da destilação apresentou os maiores teores de C16:0 e C18:0/C18:1

Considerando os ésteres de cadeia curta, C8:0, C10:0, C12:0 e C14:0, presentes no biodiesel em relação aos mesmos ésteres presentes nos destilados, tem-se uma eficiência de $11,5 \%$

Os valores de massa específica, volumes e balanço de massa são apresentados na Tabela 5.

Verifica-se também, como para o biodiesel de amêndoa de macaúba, aumento proporcional dos valores da massa específica das frações, tendo como média $870,1 \mathrm{~kg} \mathrm{~m}^{-3}$, apresentando as mesmas características de aumento de massa específica. O resíduo da destilação apresentou maior massa específica devido à maior presença de ésteres C18:0/ C18:1.

A partir do balanço de massa do processo de destilação, tem-se que $0,2238 \mathrm{~kg}$ de biodiesel foi utilizado na destilação. E foram produzidos $0,1304 \mathrm{~kg}$ de destilado e $0,0933 \mathrm{~kg}$ de resíduo da destilação, no total.

\section{CONCLUSÃO}

Dos presentes resultados sobre as composições do biodiesel 
Tabela 2. Teor de ésteres para o biodiesel de amêndoa de macaúba, frações destiladas e resíduo

\begin{tabular}{|c|c|c|c|c|c|c|c|c|}
\hline \multirow{3}{*}{ Ésteres } & \multicolumn{8}{|c|}{ Teor (\%) de Ésteres } \\
\hline & \multicolumn{8}{|c|}{ Fração } \\
\hline & Biodiesel & 1 & 2 & 3 & 4 & 5 & 6 & Resíduo \\
\hline C8:0 & 5,24 & 38,49 & 12,11 & 2,91 & 0,41 & 0,18 & 0,26 & 0 \\
\hline C10:0 & 3,48 & 11,16 & 10,54 & 7,36 & 2,96 & 0,58 & 0,27 & 0 \\
\hline C12:0 & 42,38 & 45,86 & 68,73 & 74,35 & 70,87 & 57,37 & 31,63 & 4,93 \\
\hline C14:0 & 9,06 & 2,20 & 4,92 & 8,53 & 12,20 & 16,29 & 17,20 & 4,21 \\
\hline C16:0 & 7,01 & 0,77 & 1,24 & 2,40 & 4,17 & 7,71 & 13,24 & 9,79 \\
\hline C18:0/C18:1 & 32,82 & 1,52 & 2,45 & 4,44 & 9,39 & 17,87 & 37,40 & 81,08 \\
\hline
\end{tabular}

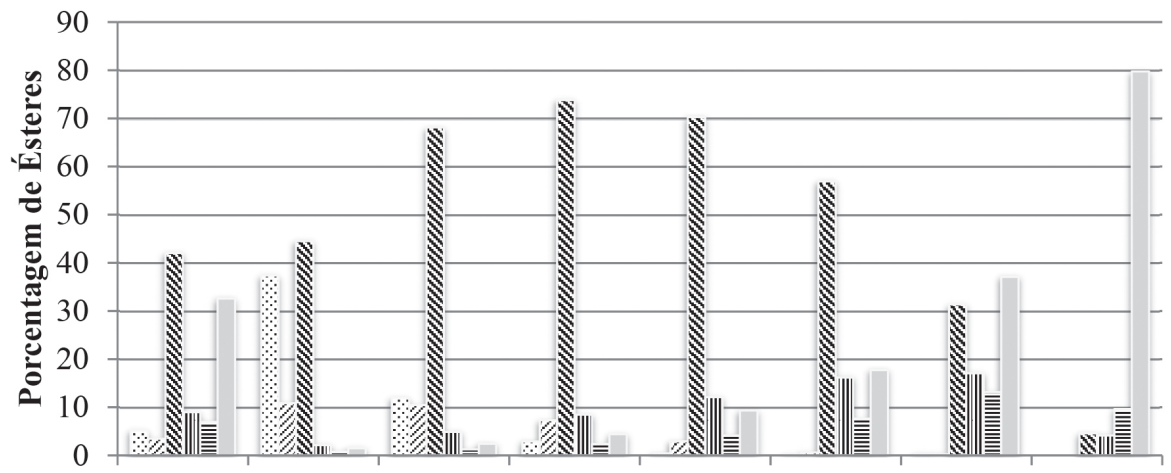

Biodiesel Fração1 Fração2 Fração3 Fração4 Fração5 Fração6 Resíduo

Amostras Macaúba

$\therefore \mathrm{C} 8 \geqslant \mathrm{C} 10 \leqslant \mathrm{C} 12$ I $\mathrm{C} 14 \equiv \mathrm{C} 16 \backsim \mathrm{C} 18 / \mathrm{C} 18: 1$

Figura 2. Teor de ésteres das frações destiladas do biodiesel de óleo de amêndoa de macaúba

Tabela 3. Massa específica a $20^{\circ} \mathrm{C}$, volume e balanço de massa para o biodiesel de amêndoa de macaúba, frações destiladas e resíduo

\begin{tabular}{lcccccccc}
\hline \multirow{2}{*}{ Parâmetro } & \multicolumn{8}{c}{ Fração } \\
\cline { 2 - 9 } & Biodiesel & 1 & 2 & 3 & 4 & 5 & 6 & Resíduo \\
\hline Massa Específica $\left(\mathrm{kg} \mathrm{m}^{-3}\right)$ & 892,0 & 850,7 & 858,9 & 869,1 & 874,6 & 879,3 & 895,7 & 922,0 \\
Volume $(\mathrm{mL})$ & 250 & 25 & 25 & 25 & 25 & 25 & 25 & 100 \\
Massa $(\mathrm{kg})$ & 0,2230 & 0,0213 & 0,0215 & 0,0217 & 0,0219 & 0,0220 & 0,0224 & 0,0922 \\
\hline
\end{tabular}

Tabela 4. Teor de ésteres para o biodiesel de palmiste, frações destiladas e resíduo

\begin{tabular}{lcccccccc}
\hline & \multicolumn{9}{c}{ Teor $(\%)$ de Ésteres } \\
\cline { 2 - 8 } Ésteres & \multicolumn{7}{c}{ Fração } \\
\cline { 2 - 9 } & Biodiesel & 1 & 2 & 3 & 4 & 5 & 0 \\
\hline C8:0 & 1,39 & 17,89 & 2,73 & 0,67 & 0,16 & 0 & 0,07 & 0 \\
C10:0 & 1,82 & 9,03 & 5,48 & 3,39 & 1,52 & 0,56 & 0,26 & 0 \\
C12:0 & 55,53 & 66,76 & 82,96 & 81,63 & 79,62 & 75,5 & 53,04 & 10,9 \\
C14:0 & 14,12 & 4,12 & 6,61 & 9,98 & 12,43 & 16,33 & 25,92 & 11,89 \\
C16:0 & 7,04 & 1,05 & 1,01 & 1,92 & 2,63 & 3,49 & 9,24 & 15,24 \\
C18:0/C18:1 & 20,11 & 1,16 & 1,21 & 2,41 & 3,64 & 4,12 & 11,47 & 61,97 \\
\hline
\end{tabular}

e de seus destilados, e das respectivas eficiências do processo de destilação atmosférica, verificaram-se as viabilidades tecnológica e econômica, com significativo ganho ambiental, em relação aos padrões convencionais, do uso do óleo de amêndoa de macaúba e óleo de palmiste como matéria-prima para produção de biodiesel rico em ésteres leves (C8:0 a C14:0). A destilação levou a destilados mais concentrados nesses ésteres, por redução da proporção nos ésteres de maior cadeia molecular. O destilado é adequado à formulação do combustível alternativo para aviação, por mistura volumétrica com o querosene fóssil de aviação (QAV), para assegurar propriedades que estejam em conformidade com a resolução ANP ㄲo37/2009. Ainda, o resíduo da destilação pode ser utilizado na mistura com 


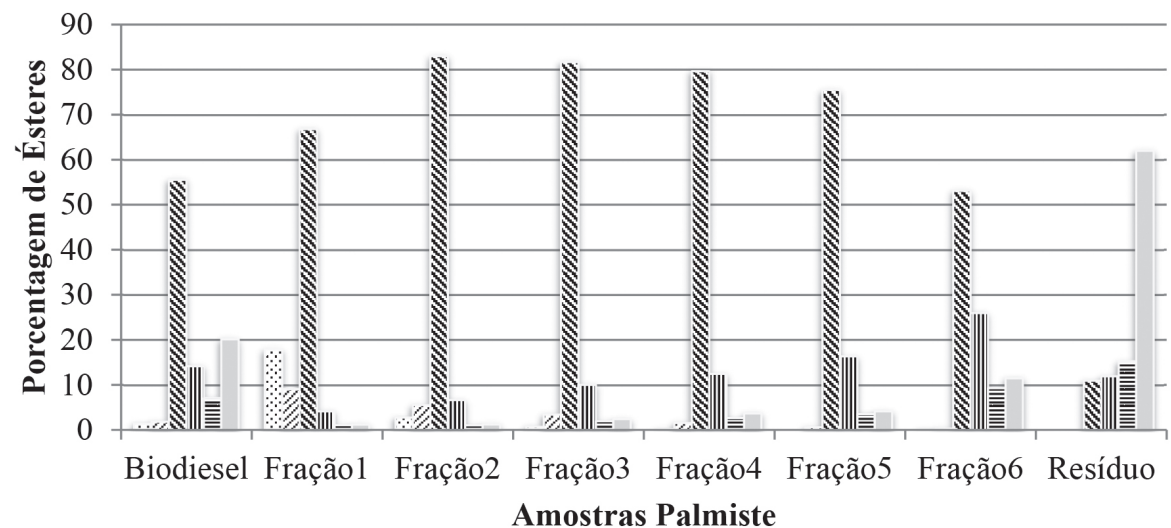

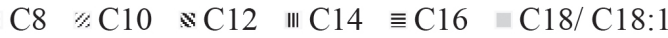

Figura 3. Teor de ésteres das frações destiladas do biodiesel de óleo de palmiste

Tabela 5. Massa específica a $20^{\circ} \mathrm{C}$, volume e balanço de massa para o biodiesel de palmiste, frações destiladas e resíduo

\begin{tabular}{lcccccccc}
\hline \multirow{2}{*}{ Parâmetro } & \multicolumn{9}{c}{ Fração } \\
\cline { 2 - 8 } & Biodiesel & 1 & 2 & 3 & 4 & 5 & 6 & Resíduo \\
\hline Massa Específica $\left(\mathrm{kg} \mathrm{m}^{-3}\right)$ & 895,0 & 849,4 & 859,0 & 865,9 & 872,7 & 879,9 & 893,7 & 933,0 \\
Volume (mL) & 250 & 25 & 25 & 25 & 25 & 25 & 25 & 100 \\
Massa $(\mathrm{kg})$ & 0,2238 & 0,0212 & 0,0215 & 0,0216 & 0,0218 & 0,0220 & 0,0223 & 0,0933 \\
\hline
\end{tabular}

o diesel, devido à presença de ésteres C18:0/C18:1, similar ao biodiesel de óleo de soja.

Da análise destes resultados, pôde-se determinar que o ponto para realizar o corte da destilação seria entre as frações sequenciais de coleta 5 e 6; na fração 6, o teor de C12:0 começa a diminuir com aumento do teor de C14:0, ainda dentro da faixa de ésteres relativamente leves, de interesse na separação.

Assim, o destilado recolhido ficaria entre 50 e $60 \%$ do total de biodiesel disponibilizado para a destilação, para uma melhor separação dos ésteres de cadeia curta (C8:0, C10:0, C12:0 e C14:0), de interesse para uso como bioquerosene alternativo de aviação nas misturas com o QAV; o respectivo resíduo da destilação, rico em C16:0 e C18:0/ C18:1, pode ser utilizado na mistura com o diesel.

Para cada $1000 \mathrm{~mL}$ de biodiesel produzido utilizando óleos vegetais ricos em ácidos graxos de cadeia curta, até $600 \mathrm{~mL}$ poderiam ser usados como combustível no transporte aéreo e $400 \mathrm{~mL}$ também no terrestre. A alternativa de uso da fração leve de ésteres do biodiesel favorece ainda os setores da agricultura familiar e os ganhos sociais às atividades extrativistas sustentáveis, com o emprego, em bases tecnológicas, de matérias-primas pouco exploradas ou negligenciadas no mercado mais capitalizado.

\section{AGRADECIMENTOS}

Os autores agradecem à Escola Técnica de Saúde (ESTES) e ao Instituto de Química (IQ) da Universidade Federal de Uberlândia (UFU).

JDF agradece ao CNPq o apoio financeiro, pela bolsa de produtividade em pesquisa, projeto \# 304958/2017-4.

\section{REFERÊNCIAS}

1. http://www.rmct.ime.eb.br/arquivos/RMCT_3_tri_2011/RMCT_059_ E5A_11.pdf, acessada em dezembro de 2018.

2. Batistella, C. B.; Maciel, M. R. W.; Silva, N. L.; Filho, R. M.; Br PI 0.803.465-6A2, 2011.

3. http://www.planalto.gov.br/ccivil_03/_Ato2011-2014/2011/Lei/L12490. htm, acessada em dezembro de 2018.

4. Blakey, S.; Rye, L.; Wilson, C. W.; Proc. Combust. Inst. 2011, 33, 2863.

5. Jansen, R. A; Second Generation Biofuels and Biomass: Essential Guide for Investors, Scientists and Decision Makers, $1^{\text {st }}$ ed., Wiley-VCH: Weinheim, 2013.

6. Liu, G.; Yan, B.; Chen, G.; Renewable Sustainable Energy Rev. 2013, $25,59$.

7. https://www.astm.org/Standards/D7566.htm, acessada em dezembro de 2018.

8. http://legislacao.anp.gov.br/?path=legislacao-anp/resol-anp/2014/ dezembro\&item=ranp-63--2014, acessada em dezembro de 2018.

9. ht t p://www.ubrabio.com.br/1891/Noticias/ CombustivelRenovavelGanhaEspacoNaAviacaoNacional_268947/, acessada em dezembro de 2018.

10. Wardle, D. A.; Renewable Sustainable Energy Rev. 2003, 7, 1.

11. http://www.biodiesel.gov.br/docs/Resolucao_63.pdf, acessada em dezembro de 2018.

12. http://www.biodiesel.gov.br/docs/Resolucao_37.pdf, acessada em dezembro de 2018.

13. Damasceno, S. M.; Ferraz, V.; Nelson, D. L.; Fabris, J. D.; AIMS Energy 2018, 6, 801.

14. Llamas, A.; García-Martínez, M. J.; Al-Lal, A. M.; Canoira, L.; Lapuerta, M.; Fuel 2012, 102, 483.

15. Oliveira, V. F. de; Parente Jr, E. J. S.; Cavalcante Jr., C. L.; F. Murilo, T. L.; The Canadian Journal of Chemical Engineering 2017, 96, 1071. 